\title{
Choirs in Two Countries - A Study of Community Music Therapy for the Older Adults in Norway and Japan
}

\author{
Hiroko Kimura $^{1}$, Yumi Nishimoto ${ }^{1}$ * $^{\text {. }}$ \\ 1 Kumamoto University, Japan \\ *pkimura@kumamoto-u.ac.jp \\ Received: 4 December 2015 ; Accepted: 10 October 2016 ; Published: 1 March 2017
}

\begin{abstract}
Modern music therapy first developed in western countries and has now spread throughout the world. This research focuses on how Japanese culture affects the implemention of Community Music Therapy (CoMT), by comparing the results of questionnaires carried out with groups of older adults in Norway and Japan. The results showed a small difference in terms of opinions expressed but significant cultural differences in the process of answering the questions set to them, which may be derived from individualistic and collectivistic cultural elements. The results are considered under five headings in the discussion section: Basic cultural difference, Self-expression, Internal relationships, Sense of community, and Role of music. We conclude that although CoMT has an important role in the social involvement of older adults regardless of cultures, cultural differences should be taken carefully into consideration.
\end{abstract}

Keywords: community music therapy, older adults, choir activity, culture, music sentence completion task, collectivism, individualism

\section{Introduction}

The issue of an aging population is of global concern ${ }^{1}$. Various welfare systems for older adults have developed in many countries, which help older adults live healthy and active lives. The growing focus on active ageing draws increased attention to musical activities for older adults. Numerous pieces of research have indicated the efficacy of musical activities for the health promotion and social participation (Bygren et al., 1996; Creech, Hallam, McQueen \& Varvarigo, 2013; Hays \& Miniciello, 2005; Hara, 2011; Lehtonen, 2002; McCullough, 1981; Ruokonen \& Ruismäki, 2011). Community Music Therapy (CoMT) has already spread throughout the world, with the intention of connecting people to community using various methods and for the benefit of various types of people. In a period of ageing populations it is likely that CoMT will increasingly contribute to solving the problems of older adults, especially for isolation and depression.

Choir activity or group singing seems to have become a key aspect in this effort, as it not only promotes individual physical and mental health but also connects people together. Although group singing has sometimes been seen as rather behind the times or only a recreational medium, recently several studies have focused on its therapeu- 
tic power (Balsnes, 2012; Clift \& Hancox, 2010; Clift \& Morrison, 2011; Cohen et al., 2006; Elefant, 2010; Grape et al., 2009; Johnson et al., 2013; Kimura, 2014; Livesey et al., 2012; Matsui, 2010; Stige, 2010; Wise, Hartmann \& Fisher, 1992; Zanini \& Leao, 2006). Recently music therapy research widened its perspective toward the notion of music and health as an integrated approach, focusing on culture and community (Ansdell, 2014; MacDonald et al., 2012; Pavlicevic \& Ansdell, 2004; Ruud, 2010, 2012; Stige, 2002; Stige et.al., 2010; Stige, 2012). CoMT seems to be launching towards a new stage of being situated in a wider context, socially and culturally.

However, these trends in music therapy have been developed mainly in Western countries and so some discrepancies may occur when introduced in non-western countries. The conditions of community differ by culture and so CoMT practice should take this into account. Similar considerations also occur in the field of Japanese social welfare, in which the chief ideas were imported from Western countries (Kuga, 2005; Shiota \& Ueda, 2011). So far, although several pieces of research on CoMT in non-Western countries have been carried out (Elefant, 2010; Inoue, 2007; Numata, 2010; Pavlicevic, 2004), more research on various cultural perspectives is needed in order to develop CoMT worldwide.

The authors of the present research have been carrying out CoMT for older people in a medium sized city of Japan for 10 years. In the course of sessions, the authors found that various collectivistic features are distinctive of our group: for example, a tendency to maintain the conformity of the group and a refraining from expressing one's opinion. Although a simple dichotomy of individualism and collectivism puts us in danger of simplifying the issues too much, missing aspects of the complicated interplay of forces within those societies, it can still be of some help when understanding cultures. The authors try to consider CoMT from the viewpoint of cultural psychology, with the collectivistic/ individualistic consideration as one key point, and to reflect on a way for CoMT to move forward by integrating the characteristics of Western/non-Western cultures.

\section{Individualism and Collectivism}

Cultures are often termed individualistic and collectivistic in various academic fields and in popular terminology. Although there has been a lot of debate concerning individualism and collectivism, we mainly mention two key researchers here. Geert Hofstede, a Dutch social psychologist, defined individualism and collectivism as follows:

Individualism pertains to society in which the ties between individuals are loose: everyone is expected to look after him- or herself and his or her immediate family. Collectivism as its opposite pertains to societies in which people from birth onward are integrated into strong, cohesive in-groups, which throughout people's lifetime continue to protect them in exchange for unquestioning loyalty. (Hofstede, Hofsted \& Minkov, 2010, p. 92)

Hofstede carried out a large survey study regarding cultural differences in many countries all over the world, with 'Individualism Index' (IDV) as one of his six dimensions. He put a score from 0 to 100 to each 76 countries and regions, with a higher score being more individualistic than lower one. He created a chart showing that Western countries, such as the United States (which he gave a score of 91 to), Australia (90), the United Kingdom (89), and the Netherlands (80) are more individualistic than the countries of Eastern Asia and Latin America, such as China (20), South Korea (18), Indonesia (14), and Guatemala (6).

Harry C. Triandis (1995), a cross-cultural psychologist, sees individualism as consisting: "...of loosely linked individuals who view themselves as independent of collectives..." and he sees collectivism as "a social pattern consisting of closely linked individuals who see themselves as parts of one or more collectives family, tribe, nation..." (p. 2). He noted that although countries such as Brazil, India, Japan, Russia are seen as being collectivist countries, and France, the United States, the United Kingdom, and 
Germany as individualistic countries, both collectivistic and individualistic elements can be found in all these countries in different combinations.

Referring to the notion of self that was mentioned by Markus \& Kitayama (1991), Triandis explains further that there are four kinds of self: independent or interdependent and same or different. Mixing them with individualism and collectivism, he proposed four categories: horizontal individualism (independent/same) and horizontal collectivism (interdependent/same), vertical individualism (independent/ different) and vertical collectivism (interdependent /different). The horizontal dimension emphasizes that people should be similar on most attributes, especially status. This reflects the "same self", which does not want to stand out. The vertical dimension accepts inequality, and that rank has its privileges. This is reflective of the "different self", which feels comfortable with competitive situations (Triandis, 1995, p. 44, p. 164). For example, Triandis suggested that middle class and upper class Americans tend toward vertical individualism, but that Sweden tends towards a horizontal individualist culture (p. 46).

\section{Individualism and Collectivism in Norway and Japan}

Considering these studies, let us focus on individualism and collectivism in Norway and Japan. Hofstede et al. (2010) reported that the IDV score of Norway is 69, and Japan 46, which suggests that Norway is more individualistic than Japan. However, the difference is not very large as some may assume (Norway: 17th out of 76 countries, Japan: 35th). The top 30 countries in the IDV score are all Western countries, so Norway ranks in the middle of this group. Japan's score is 46, which puts Japan at an only moderately low level for individualism, and the second highest among Asian countries (pp. 95-97). Therefore, Japanese might be seen as collectivistic by Western standards but seen as individualistic by Asian standards.

Triandis (1995) noted that there is a tendency towards collectivism in Scandinavian cultures where in-groups are more important and collectivism regulates behaviour more tightly in family and social settings than in the United States. He concluded that Scandinavia must be seen as a moderately individualistic region, with many horizontal collectivist elements (Triandis, 1995, pp. 98-99). Concerning Japan, he noted that vertical collectivism was a powerful cultural pattern pre-World War II, but after the war, confronting the individualism of the United States occupational forces, it shifted from vertical to horizontal collectivism. He also called attention to within-culture variations: the older Japanese are still rather vertical, and the younger generation is moving both in the horizontal direction and toward individualism (p. 89).

These studies suggest that the cultural differences between Norway and Japan, though considerable, are not so extreme as expected. Recent research on individualism and collectivism has even questioned the basic idea that Japanese are collectivistic (Takano, 2008; Yamagishi, 2002) and the idea of Americans as individualists is also open to reconsideration (Oyserman, Coon, Kemmelmeier, 2002). However, it is probably correct to say that Japanese culture is more collectivistic than Norwegian. Further research in this field will uncover more about these aspects of culture.

\section{Case Study of the Present Research}

Our analysis of two cases aims to uncover some of the ways differences might manifest and be managed. The first is our case from Japan. Since 2006 our group has conducted a CoMT project in an old shopping arcade where the older adults often visit to help promote health and create new bonds through music. At the time the present study was conducted, in 2013, we held open style sessions where everyone could drop in during their shopping. The number of the participants was about 20 (female $90 \%$, male 10\%), and the average age was about 76 (the age range was 65-87). All the participants lived in their own homes, mostly alone or in couples. Some of them had chronic diseases, and most of them lived nearby except for a few participants who lived far and came by bus. We held concerts every year, and the participants sung as performers on stage. 
The CoMT project is still ongoing, with a larger amount of participants (40-45). In general, the effects of the project so far have been very good; most of the participants feel that sessions are pleasant and good for their health. It helps them to meet various kinds of people and recreate a new sense of community.

Stige described the second case in the 2010 book Where Music Helps. A senior choir was created by a group of pensioners in Sandane in 1992, with music therapist Grete Skarpeid as the first conductor. The choir had 20 singers, aged 70-92, who had an average age above 80 . They lived in their own homes and were relatively healthy; although one member had Alzheimer's disease and lived in an institution. They gathered to sing once a week for 2 hours, some coming in from quite far away. They sometimes performed in concerts, during which their vivid and energetic singing amazed the audience (Stige, 2010, p. 246-247, p. 254-257).

Stige carried out the music sentence completion task then, in which the members could produce multiple responses to queries such as: "Music is...", "For me, singing in a choir is ... ", "When I sing, then ...," "Without music ... " He also established a collaborative exploration with Solgunn Knardal, a music therapist and the conductor of the choir at that time, who interviewed all the members of the choir as part of her thesis. Stige gave detailed reflections on the choir, using the results of the task and the interviews as empirical material.

These cases from two very different countries share common features: the participants were well-older adults living in their own homes and participated in choir activity once a week. A similar number of participants were involved (about 20), and they also performed at concerts in collaboration with young students. The points of difference are: the Japanese members were a little younger than the Norwegians; there were more men in the Norwegian group than in the Japanese group; the session duration time of the Japanese group was half of that of the Norwegian group; most of the Japanese members lived nearby, whereas some of the Norwegian members lived quite far away. A final difference is that the Japanese participants lived in a much bigger and more urban area. Although such differences exist, we considered much of the basic therapy conditions to be similar.

Stige and his colleagues gave us permission to use the 'music sentence completion task' for our study. Stige also proposed we add two further queries, in order to develop further understanding of the interpersonal relationships within the group: "My cosingers in the choir are...," and "The conductor of the choir is...". Our aim in this research is to understand how culture influences CoMT, and to use that information to help us consider how can we help older adults to live a more vivid and sociable life.

\section{Method}

The method we adopted is a case comparison of the results of the same open completion task carried out in two countries, Norway and Japan. We did not set out to replicate the Norwegian case; rather we used existing data.

\section{Participants}

The Norwegian participants were 15 members of the Senior Choir who were present on a rehearsal day (Stige, 2010, p. 258). The Japanese participants were19 members of the CoMT project who were present on a rehearsal day in 2013.

\section{Measures and Procedure}

In Norway, the music sentence completion task was distributed to the participants on a rehearsal day and they filled it in after the break, just before they started singing. Fourteen participants filled in the form themselves and Solgunn Knardal, the conductor, helped the one participant with Alzheimer's disease (Stige, 2010, p. 250 \& p. 258).

In Japan, the music sentence completion task was distributed to 19 participants (18 females, one male) on a rehearsal day in 2013 before the session started. The re- 
Table 1. Music is...

Norwegian information taken from Stige (2010, p. 258).

\begin{tabular}{|c|c|c|}
\hline & Norway (15 respondents) & Japan (19 respondents) \\
\hline $\begin{array}{l}\text { Number of } \\
\text { statements }\end{array}$ & 43 (1-4 statements per respondent) & 24 (1-3 statements per respondent) \\
\hline \multirow[t]{5}{*}{ Content } & $\begin{array}{l}\text { Most of the responses focused upon music in relation to } \\
\text { the individual, or on more general and abstract qualities } \\
\text { of music(s) and situations. }\end{array}$ & $\begin{array}{l}\text { All responses focused upon music in relation to the indi- } \\
\text { vidual, and none gave statements on more general and } \\
\text { abstract qualities of music. }\end{array}$ \\
\hline & $\begin{array}{l}14 \text { respondents reported on positive experiences and ef- } \\
\text { fects of music. } 11 \text { used phrases such as "Music is encour- } \\
\text { aging" and "Music is...an experience, [it] gives me tran- } \\
\text { quility, happiness, and also harmony." The others used } \\
\text { briefer statements, like "Music is absolutely necessary" } \\
\text { (two respondents), "Music is part of life," "Music is alive," } \\
\text { and "Music is everything for me." One respondent gave } \\
\text { the clear view that "To sing in a choir is, without doubt, } \\
\text { therapy." }\end{array}$ & $\begin{array}{l}\text { All respondents reported on positive experiences and ef- } \\
\text { fects of music. They used phrases such as "Music is a } \\
\text { reason for living" (seven respondents), " Music is my } \\
\text { power," (one respondent),"pleasure" (three respon- } \\
\text { dents)," "relieving stress" (three respondents), "healing } \\
\text { of the heart," "Music can give a sense of ease and hope } \\
\text { in our heart," and one respondent stated that "I thought } \\
\text { that music was unrelated to me, but it became more fun, } \\
\text { day by day." }\end{array}$ \\
\hline & $\begin{array}{l}\text { Three respondents gave responses that underlined rela- } \\
\text { tionships between music and community: "Music is con- } \\
\text { tributing to a positive atmosphere," “Music uplifts, } \\
\text { loosens up, and connects," “ To perform is social and cre- } \\
\text { ates a sense of community." }\end{array}$ & $\begin{array}{l}\text { One respondent gave a response on the connection with } \\
\text { community, "Music is making friends." }\end{array}$ \\
\hline & $\begin{array}{l}\text { One respondent gave more 'neutral' descriptions, such as } \\
\text { "Music is song, waves on the beach, instruments, orches- } \\
\text { tra." }\end{array}$ & $\begin{array}{l}\text { No respondents gave statements on 'neutral' description } \\
\text { of music. }\end{array}$ \\
\hline & $\begin{array}{l}\text { Three respondents qualified their positive statements, } \\
\text { requesting that music should be of the right sort: "not } \\
\text { too noisy," "not jazz," and "not black metal." }\end{array}$ & $\begin{array}{l}\text { No respondents gave statements relating to the sort of } \\
\text { music. }\end{array}$ \\
\hline
\end{tabular}

searchers told the participants that they were free to write anything they wished or not to answer at all, if they preferred, and that there would not be any consequences if they did not submit the questionnaire. The researchers also told them that the answers should be submitted without names and be put into envelopes, to insure anonymity. The researchers explained that the results were only to be used in this project, and the participants who agreed to these aspects were welcome to take part. Eleven people submitted on that day and another eight people took the paper home and submitted it on the next rehearsal day. They all filled it in themselves.

The Norwegian data was taken from Stige's two chapters, Chapter 17, "Action; Caring for Music: The Senior Choir in Sandane, Norway" (p. 245-251) and Chapter 18, "Reflection; Practicing Music as Mutual Care" (p. 253-274) in the book Where Music Helps (2010). In these chapters there is a lot of information, including the survey answers, the participants' comments, the descriptions of the conditions, the process of the sessions, and the background of the participants. We compared his points with our results. The two studies were not originally designed to be considered together. Nevertheless, we felt that some kind of comparison of results would be useful for understanding aspects of the cultural issues involved in CoMT.

\section{Results}

Below (Tables 1-6) are the results of each query in two columns. After the tables a short summary of the results is presented. 
Table 2. For me singing in a Choir is...

Norwegian information taken from Stige (2010, p. 260).

\begin{tabular}{|c|c|c|}
\hline & Norway (15 respondents) & Japan (19 respondents) \\
\hline $\begin{array}{l}\text { Number of } \\
\text { statements }\end{array}$ & 39 & 24 \\
\hline \multirow[t]{5}{*}{ Content } & $\begin{array}{l}\text { There was more focus upon community and collabora- } \\
\text { tion and } 11 \text { respondents expressed this with these words: } \\
\text { "...fellowship," “...nice to be part of," "social," "humane," } \\
\text { and "to use your voice in community." }\end{array}$ & $\begin{array}{l}\text { There appeared to be less sense of a bond and commu- } \\
\text { nity and seven respondents expressed this with these } \\
\text { words: "a bond," "a link with everybody," "good relation- } \\
\text { ship," "make many friends," and "...everyone's heart be- } \\
\text { comes as one." }\end{array}$ \\
\hline & $\begin{array}{l}\text { Most of the respondents gave responses that linked } \\
\text { singing to positive personal experiences. They described } \\
\text { singing in a choir as "...the best entertainment," "very } \\
\text { nice," etc., with effects such as "good mood" and "joy," } \\
\text { and gave valuations such as "something I'll never have } \\
\text { enough of." }\end{array}$ & $\begin{array}{l}\text { Nine respondents gave responses that linked singing to } \\
\text { positive personal experiences. They described singing in } \\
\text { a choir as "pleasure," "feel happy," "relieving stress," "feel } \\
\text { reassured," "get a sense of hope," "comfortable," and } \\
\text { gave valuations such as "Music can be like mental gym- } \\
\text { nastics." }\end{array}$ \\
\hline & $\begin{array}{l}\text { Seven respondents focused upon singing as aesthetic } \\
\text { experience: "Nice to listen to," “Not possible to express in } \\
\text { words," "If the choir is in tune and in balance and have } \\
\text { some good voices, then it's very beautiful," and "I can ex- } \\
\text { press and use myself in different ways than in other situ- } \\
\text { ations." }\end{array}$ & $\begin{array}{l}\text { Two respondents focused upon singing as aesthetic ex- } \\
\text { perience: “...it is a pleasure to make harmony with them," } \\
\text { and "All of things which I see and hear are shining." }\end{array}$ \\
\hline & $\begin{array}{l}\text { Five respondents described singing in a choir as cogni- } \\
\text { tive engagement and stimulation, with statements such } \\
\text { as: "Inspiration," "Concentration," and "Reminiscence." }\end{array}$ & $\begin{array}{l}\text { One respondent described singing in a choir as cognitive } \\
\text { engagement with a statement that "learn various music } \\
\text { that I didn't know." }\end{array}$ \\
\hline & $\begin{array}{l}\text { No responses which focused upon a physical aspect were } \\
\text { noted. }\end{array}$ & $\begin{array}{l}\text { One respondent focused upon a physical aspect: "main- } \\
\text { taining my heart and lungs." }\end{array}$ \\
\hline
\end{tabular}

\section{Summary}

Concerning the first query, "Music is...", the number of the Norwegian statements (43) was almost twice as large as in the Japanese case (24), and the Norwegians used a wider vocabulary than the Japanese. Most of the respondents, in both cases, mentioned positive experiences and the positive effects of music (in Norway: 93\%, in Japan: 100\% responded in this way). Three Norwegian respondents talked about the social aspects of music, but only one Japanese person did so. General or abstract aspects of music were mentioned in the Norwegian statements, whereas none of the Japanese respondents referred to abstract qualities of music. The Japanese respondents seemed to see music as a personal matter, as their answers mainly focused on the relationship between music and themselves, such as "a reason for living" (seven respondents), "my power", or "pleasure". The Norwegians gave some clear opinion as to types of music they did not like, but the Japanese did not do so. This may be an example of individualistic and collectivistic thinking, in that the Norwegians thought it okay to say things directly, whereas the Japanese often think of that as being rude or too self-assertive.

As to the second query, "For me singing in a Choir is...", there was more focus on community in the Norwegian statements than the Japanese one. In Norway, 73.3\% (11 out of the 15 respondents) gave statements focusing on community and collaboration, whereas in Japan $36.8 \%$ (7 out of 19 respondents) mentioned choir activity as a type of bond (community). This seems rather to contradict the general opinion of Japanese society that it has a more group focused character. Seven respondents $(46.7 \%)$ of the Norwegian respondents focused on the aesthetic experience of singing in the choir, 
Table 3. When I sing, then...

Norwegian information taken from Stige (2010, p. 260).

\begin{tabular}{|c|c|c|}
\hline & Norway (15 respondents) & Japan (19 respondents) \\
\hline $\begin{array}{l}\text { Number of } \\
\text { statements }\end{array}$ & 29 & 30 \\
\hline \multirow[t]{5}{*}{ Content } & $\begin{array}{l}\text { The statements given were more personal, reflecting } \\
\text { emotional experiences, contact with the body, and mo- } \\
\text { ments of identity and transcendence. } \\
14 \text { statements were on emotional experiences, including } \\
\text { statements on positive emotions ("I have a good feeling," } \\
\text { "I become happy and uplifted," etc.) and more painful } \\
\text { emotions ("I feel a variety of emotions; grief, sadness," “I } \\
\text { express frustration, sorrow"). } \\
\text { There was one statement on more long-lasting moods } \\
\text { with behavioral implications: "I am thriving in my work." }\end{array}$ & $\begin{array}{l}\text { The statements given were mostly personal, reflecting } \\
\text { emotional experiences and contact with the body. } \\
25 \text { statements focused upon positive emotional experi- } \\
\text { ence: "My mind is healed," “My feeling gets better," "feel } \\
\text { pleasant," "forget to be sad and feel bright," "relieve } \\
\text { stress," "get rid of uneasiness," "getting more lively," “My } \\
\text { cold heart is getting warm," "feel peace of mind." } \\
\text { No statement mentioned painful emotions. } \\
\text { Two statements were about long-lasting moods: “I can } \\
\text { change my mood and I can have a happy day," and "I can } \\
\text { forget to be lonely and sad, and I can have a pleasant } \\
\text { day." }\end{array}$ \\
\hline & $\begin{array}{l}\text { There were a few statements that more or less explicitly } \\
\text { mentioned the body: "I relax," “My breathing calms } \\
\text { down," “I become quickened," “I become more balanced, } \\
\text { so that I keep my voice in shape." }\end{array}$ & $\begin{array}{l}\text { There were two statements that mentioned physical } \\
\text { change: "I can forget my bodily pain," and "After singing, I } \\
\text { feel hungry and I can enjoy a delicious lunch." }\end{array}$ \\
\hline & $\begin{array}{l}\text { Five or six statements could be labeled statements on } \\
\text { identity, with a touch of transcendence, e.g. "I am not so } \\
\text { alone," “The sounds of the song carry me," “I am part of } \\
\text { something that gives meaning to life," “I find myself(es- } \\
\text { pecially when we sing hymns)," "I dream," and "I am } \\
\text { where I ought to be." }\end{array}$ & There was no statement on identity and transcendence. \\
\hline & $\begin{array}{l}\text { There was one statement about personal responsibility: } \\
\text { "As a choir member you need to sing." }\end{array}$ & $\begin{array}{l}\text { There was one statement on a preferable direction of the } \\
\text { choir: "I don't like a choir that practices only the same } \\
\text { songs and competes in a contest." }\end{array}$ \\
\hline & $\begin{array}{l}\text { Three statements were about the possibility of using and } \\
\text { training cognitive functions: "I sharpen my memory," "I } \\
\text { may use my thoughts, memories, and words," and "I may } \\
\text { express emotions and thoughts." }\end{array}$ & $\begin{array}{l}\text { There were no statements on the possibility of using and } \\
\text { training cognitive functions. }\end{array}$ \\
\hline
\end{tabular}

whereas only 10.5\% (two respondents) of the Japanese respondents mentioned aesthetic experience, which suggests that the Japanese respondents had less interest in considering abstract notion of music in connection to their personal experiences or feelings.

As to the third query, "When I sing, then...", the number of the statements is almost the same (Norway: 29, Japan: 30), and the number in the Japanese case is the largest amount given in all the six queries. As this query is focused on private feelings, the Japanese respondents might have felt it easier to answer. While $83.3 \%$ (25 statements) of the Japanese statements were focused upon positive emotional experiences, the Norwegian statements were more varied, such as: positive or painful emotional experience (48.3 \%: 14 statements); statements on identity and transcendence (five or six statements: $17.2-20.7 \%$ ); possibility of using and training cognitive functions (three statements: $10.3 \%)$. 
Table 4. Without music...

Norwegian information taken from Stige (2010, p. 261).

\begin{tabular}{|c|c|c|}
\hline & Norway (15 respondents) & Japan (19 respondents) \\
\hline $\begin{array}{l}\text { Number of } \\
\text { statements }\end{array}$ & 22 & 24 \\
\hline \multirow[t]{2}{*}{ Content } & $\begin{array}{l}22 \text { statements were produced in response but one re- } \\
\text { spondent refused to make a statement and another re- } \\
\text { futed the open phrase itself ("It is not possible"). }\end{array}$ & $\begin{array}{l}24 \text { statements were produced in response and one re- } \\
\text { spondent questioned the query itself ("I cannot think } \\
\text { about a world in which there is no music. I am always } \\
\text { singing in my heart"). }\end{array}$ \\
\hline & $\begin{array}{l}\text { Of the remaining statements } 18 \text { focused upon the de- } \\
\text { scription of a flat, sad, and grey world, for instance: } \\
\text { "Everyday life would become deprived," "It would be so } \\
\text { silent," “It would be empty," "It would be sad," “The world } \\
\text { would become grey," and "Life would be cheerless." And } \\
\text { one statement noted the single word: "Alone." } \\
\text { Two statements suggested countermeasures: "I would } \\
\text { need to troll," “Music is a habit. When I have no music } \\
\text { around, I sing, and then I can enjoy everyday life." }\end{array}$ & $\begin{array}{l}\text { Of the remaining statements } 11 \text { focused upon the nega- } \\
\text { tive feelings: “I would feel sad and lonely," “I would get } \\
\text { discouraged," “I would lose pleasure," etc.. } \\
\text { Six statements described the grey world and meaning- } \\
\text { less life: “The world would become dark," “I would be in } \\
\text { darkness," “I would lose a reason for living” etc.. } \\
\text { Five statements noted the possibility of getting sick: “I } \\
\text { will get senile dementia," “I may be conquered by a dis- } \\
\text { ease," “I may have depression," and “I would be one old } \\
\text { woman staying indoors all day." And one statement sug- } \\
\text { gested: “I would hardly sing." }\end{array}$ \\
\hline
\end{tabular}

As to the fourth query, "Without music...", the number of the Norwegian statements (22) was the smallest of the four queries considered, and less than the Japanese number for this query (24). The reason of this is not clear, but the Norwegians might have thought that they had to hurry to complete the latter questions, as the task was carried out after the break, just before they started to sing again. The content of answers do not show much difference between two countries. Both Norwegian and Japanese respondents wrote: "I will feel lonely," "The world will become dark," "I will lose a reason for living," etc. Eighteen of the Norwegian statements (81.8\%) focused upon the description of a sad and grey world, whereas $25 \%$ (six statements) of the Japanese statements focused on a grey world. The Japanese respondents tended to focus more upon their own mental and physical states, 45.8\% (11 statements) of the Japanese statements were on the negative feelings and $20.8 \%$ (five statements) were on the physical damage (getting sick or dementia). The Norwegian respondents might be more optimistic, as two statements mentioned the countermeasures they may take if they were without music and two respondents outright rejected the query itself as an impossibility. One Japanese statement also questioned the basis of the query itself. The people of both countries seemed to feel that music, or singing in the choir was an indispensable part of their lives.

As to the fifth query, "My co-singers in the choir are...", 73.7\% (14 respondents) of the Japanese group wrote that the members of the choir were nice and pleasant, and $15.8 \%$ (three respondents) of them answered in a more concrete way, such as the name of the choir and the number of the choir members. Concerning the Norwegian respondents, Stige wrote that they were active and autonomous, taking a positive role in running the choir. Stige observed a strong sense of hospitality, also of community and friendship among the participants. He noted that they claim choir singing is social. The Norwegian group had a board to discuss organizational aspects, which seemed to encourage mutual relationship. The Japanese group had no board and did not take part in organization.

As to the sixth query, "The conductor of the choir is...", all of the Japanese respondents gave a positive evaluation, in which $61.5 \%$ (16 statements) were focused on the 
Table 5. My co-singers in the choir are...

Table 5 presents the results of one of the new queries suggested by Stige, so only the Japanese results can be given. 19 people gave one or two statements in their responses, and altogether 26 statements were given. To compare with the Norwegian situation, we summarized sentences that seemed to be related to the topic in Stige's chapters, “Action; Caring for Music: The Senior Choir in Sandane, Norway" and "Reflection; Practicing Music as Mutual Care". To balance these descriptions, we added some reflections into the Japanese column.

\begin{tabular}{|c|c|c|}
\hline & Norway & Japan (19 respondents) \\
\hline $\begin{array}{l}\text { Number of } \\
\text { statements }\end{array}$ & & 26 \\
\hline \multirow[t]{3}{*}{ Content } & $\begin{array}{l}\text { The participants are active and autonomous, taking } \\
\text { positive roles in running the choir (Stige, 2010, p. } \\
\text { 246-249). } \\
\text { Stige mentioned the comments of participants who } \\
\text { challenge negative images of older people after the } \\
\text { successful concert: "Well, at least we smashed some } \\
\text { misled prejudgments, again" (ibid. p. 247). } \\
\text { Stige noted that some found the melody new and diffi- } \\
\text { cult, with some challenging intervals and harmonies. } \\
\text { They had to try several times, with some saying that } \\
\text { they were never going to make it. But others encour- } \\
\text { aged them, saying: “Oh yes we are. Of course we are go- } \\
\text { ing to make it. In time!" (ibid. p. 248) }\end{array}$ & $\begin{array}{l}\text { The participants are familiar with each other but do not } \\
\text { take positive roles in running the choir. } \\
\text { Fourteen respondents wrote that the members of the } \\
\text { choir are nice and pleasant, such as: "friends" (seven re- } \\
\text { spondents), "Everyone is good" (six respondents), "kind" } \\
\text { (one respondent). } \\
\text { Three respondents answered in a more concrete way, such } \\
\text { as: "It's KSG20" (the name of the choir, two respondents), } \\
\text { or "About } 20 \text { " (the number of members, one respondent). } \\
\text { There were six statements which did not have a direct re- } \\
\text { lation to the query, but expressed positive feelings con- } \\
\text { cerning the group, such as: "There is singing and laughing," } \\
\text { "I am happy that I can listen to the sound of the Chinese } \\
\text { fiddle by my side," “I think the number of people is just } \\
\text { right," "We're about the same age," “I'm looking forward to } \\
\text { next week," and "I hope that everybody can be well." }\end{array}$ \\
\hline & $\begin{array}{l}\text { They had a board to discuss organizational aspects } \\
\text { (ibid. p. 249, p. 271). }\end{array}$ & $\begin{array}{l}\text { They had no board and usually followed what the staff } \\
\text { suggested. }\end{array}$ \\
\hline & $\begin{array}{l}\text { Stige observed a sense of hospitality, for instance when } \\
\text { they asked him to join in the singing (ibid. p.246). } \\
\text { One singer that was quite new in town explains the in- } \\
\text { tensity of the experience in the following way: “...I used } \\
\text { to be new here... I knew nobody else, but today I would } \\
\text { say that I think of us as a really good group of friends. } \\
\text { Or: we are siblings; singer-siblings..."(ibid. p. 266). } \\
\text { Six of the singers reflected on Lilly, who is the only in- } \\
\text { stitutionalized member (due to Alzheimer`s disease and } \\
\text { severe dementia). They emphasized that choir partici- } \\
\text { pation seems to be helpful for Lilly, and how her partic- } \\
\text { ipation is good for them too. This showed an awareness } \\
\text { that different people have different needs and how the } \\
\text { singers encouraged and supported each other. } \\
\text { Many singers talk about a strong sense of community } \\
\text { and friendship. They claim choir singing is social (ibid. } \\
\text { p. 266). } \\
\text { Another singer describes the choir as a team and em- } \\
\text { phasizes how much she enjoys being part of it (ibid. p. } \\
\text { 267). }\end{array}$ & $\begin{array}{l}\text { Three respondents wrote about the harmonious atmos- } \\
\text { phere: "I can talk with them without reserve," "Everybody } \\
\text { is harmonious, and the atmosphere is very good," "They } \\
\text { are always smiling, bright and cheerful." }\end{array}$ \\
\hline
\end{tabular}


Table 6. The conductor of the choir is...

Table 6 presents the second of the new queries suggested by Stige, so it follows the same style as above. Nineteen people gave one or two answers in their responses, and altogether 26 answers were given.

\begin{tabular}{|c|c|c|}
\hline & Norway & Japan (19 respondents) \\
\hline $\begin{array}{l}\text { Number of } \\
\text { statements }\end{array}$ & & 26 \\
\hline Content & $\begin{array}{l}\text { Stige notes: "The importance of the conductor is men- } \\
\text { tioned by most choir members, and the singers produce } \\
\text { a range of statements on what her role and contribution } \\
\text { is." (Stige, 2010, p. 267) Stige notes: "One of the more } \\
\text { common remarks is that the conductor is a very positive } \\
\text { person, encouraging them with humor, attention, and } \\
\text { positive remarks but also providing relevant feedback } \\
\text { when that is required. In other words, a high degree of } \\
\text { mutual trust seems to be involved. The singers describe } \\
\text { the conductor as having an engagement that goes be- } \\
\text { yond just conducting; there is an interest for each singer, } \\
\text { they explain." (ibid. p. 267) } \\
\text { Stige notes that they sometimes mentioned her quite } \\
\text { concrete help, such as the music notation less demand- } \\
\text { ing to read, distributing music sheets they lost, or speak- } \\
\text { ing clearly. Other times the processes are much more } \\
\text { subtle, as noted by one participant: “... and there is con- } \\
\text { tact, you know. Well, think of just the eye contact. That's } \\
\text { a very good thing for me, to be able to look the conduc- } \\
\text { tor into her eyes and things like that ... (female singer, } 79 \\
\text { years old)."(ibid. p. 267-68) }\end{array}$ & $\begin{array}{l}\text { All answers gave a positive evaluation regarding the con- } \\
\text { ductor, such as: "excellent," "good," or "nice." } \\
16 \text { statements were connected to the conductor's charac- } \\
\text { ter, such as: "She is kind and cheerful," "She is pleasant," } \\
\text { "She is intelligent and good." } \\
\text { Seven statements referred to the conductor's leadership } \\
\text { as a teacher: "She teaches us in a way that is easy to un- } \\
\text { derstand," "She is good at teaching," “I am grateful that I } \\
\text { could have a chance to meet a good teacher." } \\
\text { Three statements mentioned the atmosphere she cre- } \\
\text { ates: "She livens us up," "Her chat in the intervals of } \\
\text { singing is pleasant," and "She treats everybody equally." } \\
\text { No answers referred to the conductor's support for each } \\
\text { member. However, it was partly because we have several } \\
\text { members of staff to take care of each participant when } \\
\text { they were in need of care, such as finding the right sheet } \\
\text { of music, providing an extra copy, etc. }\end{array}$ \\
\hline
\end{tabular}

conductor's character, $26.9 \%$ (seven statements) referred to the conductor's leadership as a teacher, and $11.5 \%$ (three statements) mentioned the atmosphere the conductor created. The Norwegian members also gave a high evaluation to their conductor, on her positive character, her interest for each member, and her relevant feedback to the members, which provided a high degree of mutual trust among them. The Japanese members seemed to pay more attention to the conductor's personal character than the ability of conducting or managing the choir, whereas the Norwegian members seemed to focus more on the quality as a conductor than her personal character.

\section{Discussion}

The results above seem to uncover several cultural differences that are embedded in the both countries, and we would like to consider them from the cultural psychological point of view. Cultural psychology is a field in psychology that became a major force in the 1980s (Kitayama \& Cohen, 2007, p. xiii), and along with social psychology, research in this field has highlighted several basic characteristics of Japanese culture. So far, a lot of research on Japanese culture has been carried out in comparison with the United States, the most individualistic country according to Hofstede's score, but with far less comparative research between Japan and European countries. So, any conclusions regarding cultural differences between Japan and European countries would be rather tentative, especially in the case of Scandinavian countries, which show more collectivistic aspects than the United States. However, we can move forward in some small way by a consideration of the issues of cultural difference between Norway and Japan, and this may offer some new aspects to reflect on for music therapy. These is- 
sues can be considered under five headings: Basic cultural difference, Self-expression, Internal relationships, Sense of community, and Role of music.

\section{Basic Cultural Differences}

\section{Analytic and Holistic}

Along with individualistic and collectivistic characteristics, a lot of research has focused on another cultural difference between West and East. An American social psychologist, Richard E. Nisbett (2003), focused upon differences in ways of thinking between European-Americans and East Asians. He explained that modern Westerners tend to view the world in an analytic way and East Asians in a holistic way. Through historical survey and experimental results, he concluded that people in East Asia regard the world as complex and highly changeable and its components as interrelated. They are skilled in observing relationships between events, seeing a great deal of the field, especially background events. On the contrary, modern Westerners see the world in analytic, atomistic terms, seeing objects as discrete and separate from their environments, and they feel themselves to be personally in control of events. He pointed out that these different worldviews can be associated with different kinds of causal explanations for the same event:

If some people view the world through a wide-angle lens and see objects in contexts, whereas others focus primarily on the object and its properties, then it seems likely that the two sorts of people will explain events quite differently. People having a wide-angle view might be inclined to see events as being caused by complex, interrelated contextual factors whereas people having a relatively narrow focus might be prone to explain events primarily in terms of properties of objects. (Nisbett, 2003, p. 109)

As analytical thinking is closely connected with logical thinking and clear, ordered expression in words, some ability in verbal expression may have a high level of importance for Western people. Whereas for East Asians the focus may be more on 'relationship' or 'atmosphere' in which subtle meanings are difficult to express in words. It may be considered unnecessary or even ugly to express them.

In the present study the different tendencies, towards using a greater or lesser amount of words, is clear both in the number and the content of answers. The number of the Norwegian answers was, for the most part, larger than the Japanese answers, and with more variety of vocabulary. The results of the first query clearly show this difference. The first query, "Music is...", focused on an abstract aspect in music and participants could choose to answer either in an abstract way or in a practical way. The Norwegian answers had larger number of sentences than Japanese and the content of the answers was more varied, ranging from personal feelings to rather abstract aspects of music. The Japanese tended to use a similar vocabulary, such as "pleasure", "a reason for living", and "healing of the heart", and their sentences were relatively brief. The Norwegians used more vocabulary in answering than the Japanese did, which may suggest that Norwegians are used to explaining their inner thoughts with words more, whereas Japanese generally try to let others understand them without directly focused words, but instead, with gestures or an ability to "read the atmosphere". Japanese people tend to think everything depends on situation and so everything can be changed, which led them to use words not in a strict way but a rather ambiguous way. These elements should perhaps be taken into account when designing and analyzing questionnaires for Japanese people.

\section{Independent and Interdependent}

Markus and Kitayama (1991), cultural psychologists in the United States and Japan, pointed out that there are two construals of the Self: independent and interdependent. The independent construal of the self involves a conception of the self as an autonomous, independent person. In contrast, the interdependent construal involves seeing oneself as part of an encompassing social relationship and understanding that one's 
behavior is dependent on what the actor perceives to be the thoughts, feelings, and actions of others in the relationship (p. 226-227) ${ }^{2}$.

The interdependent characteristic was clearly seen in the attitude toward answering the music sentence completion task: the Norwegians wrote autonomously, the Japanese wrote heteronomously. Stige noted this regarding the way the Norwegian participants answered the tasks:

They are deep in concentration as they do it. Part of the time it's so silent that you could have heard a pin drop, the main exception from the silence being the conversation that develops between Solgunn and Lilly, the one member of this choir that has reached a severe stage of dementia due to Alzheimer's disease. (Stige, 2010, p. 250)

On the contrary, the Japanese participants answered by mutual agreement in active, rather light hearted, discussion. They asked their neighbor what they thought, and then wrote their answers in reference to other's opinions. They tend to discuss or chat rather than reflect on the matter, and give priority to other's opinions rather than their own. Perhaps they might not intend to hide or oppress themselves consciously, or feel that they are forced to do so by someone, they might, instead, do so just because they thought it would be preferable or safer for them. Normally, Japanese people first take consideration of others and decide their attitude or thought by balancing with them. They may not act or think totally the same as others but there appears to be a strongly imbedded habit of choosing something that will not disturb the harmony of the group.

People from individualistic cultures may feel such Japanese behavior is odd. It is taken for granted by people from such cultures that individuals differ, with each having his/her own independence for deciding issues. In a society of such autonomous individuals discussion or debate is an ordinary process used to attain objectives or agreement. But, as noted above, the Japanese participants wrote their answers as part of a collective social process, where the thoughts and actions of others were far more relevant.

The writings of Nisbett, Markus and Kitayama suggest some similarity with individualism-collectivism theory. Although there will always be individuals who differ from the norm and cases in which unusual behavior arises, the general cultural differences should be taken into account when carrying out music therapy sessions.

\section{Self-expression}

As musical performance is strongly connected to self-presentation, to consider how people in the both countries express themselves will be helpful to understanding both choirs. As a whole, the Japanese participants seemed to restrain themselves more than the Norwegians. In the third query, "When I sing, then...", the Norwegian members noted their emotional experiences (including painful ones), body, identity, or cognitive functions, whereas the Japanese focused mainly on changes in their personal positive feelings, and there was no statement on identity and transcendence. The Japanese members did not openly express this romantic aspect of the self. We suppose that this does not mean that the Japanese participants actually feel less painful feelings or have less romanticism than the Norwegian participants. It may derive from a cultural difference, as Japanese tend to restrain themselves in expressing their true feelings or thoughts, in order to maintain the harmony of the group. Although it is an anonymous open completion task in which people do not have to worry about the possibility that someone will know what you wrote, the habit of restraining the self may be too strong.

\section{High-context and Low-context}

The characteristic mentioned above, of not expressing oneself openly, may be connected to another cultural difference concerning the way people think about the context they live in. Edward T. Hall (1976), a cultural anthropologist, suggested that there are two types of cultures: High-context cultures and Low-context cultures. In High-context cultures people are deeply involved with each other and information is widely shared, 
therefore simple messages with a deep meaning flow rather freely. Whereas, in Lowcontext cultures, people are highly individualized and somewhat alienated, and have relatively little involvement with other people (p. 39). Hall categorized Japan as a High-context culture and Western countries as Low-context ones. Larry A. Samovar \& Richard E. Porter (2004) pointed out that one reason that meanings often do not have to be stated verbally in High-context cultures is that people are very homogeneous. On the other hand in Low-context cultures, the population is less homogeneous and so the verbal message contains most of the information and very little is embedded in the context or the participants. They stated that the Asian mode of communication (Highcontext) is often vague, indirect, and implicit, whereas Western communication (Lowcontext) tends to be direct and explicit (p. 76-78). One of the reasons why Japanese people take a restrained attitude in expressing themselves might be connected to their sense of High-context, in which they feel they are understood by others without much need for clarifying words.

Furthermore, Hall mentioned an interesting aspect of Japan:

The Japanese are pulled in two directions. The first is a very high-context, deeply involved, enveloping intimacy that begins at home in childhood but is extended far beyond the home. There is a deep need to be close, and it is only when they are close that they are comfortable. The other pole is as far away as one can get. In public and during ceremonial occasions (and there are ceremonies of a sort every day, even when people meet), there is great emphasis on self-control, distance, and hiding inner feelings. (Hall, 1976, p. 66-67)

In the case of our present study to write answers in the music completion tasks may make the Japanese respondents feel that they were doing something "public", especially with the group leader present. This may have led them to "switch on" the element of self-control and the hiding of inner feelings. For them, the closeness of singing together may be comfortable; it may be an example of the first aspect that Hall refers to above, as an aspect of "high-context-ness". However, to feeling like they were now being tested or some kind of official inquiry was now happening, where they had to write something down may be seen as quite another thing. This may even apply to those who took the form home to fill it out later ${ }^{3}$.

\section{Songs as a therapeutic device for reducing stress}

In addition, it is interesting that the largest number of Japanese answers for the first query was that music is "A reason for living" (seven answers), which is more than twice many as "Pleasure" (three answers). This suggests that for Japanese participants singing in a choir, or music in general, has a deep meaning in their lives, it's more than a pleasure or a pastime. It seems that these results also mirror a feature of Japanese culture. As said above, Japanese people tend not to open their feelings or thoughts, especially if it may disrupt the harmony of the group. This sometimes causes stress in individuals. Singing in a choir may function as a form of stress reduction, as they can express their feelings indirectly through the songs.

Tomiko Kojima (1994), a Japanese ethnomusicologist, states that, for Japanese people, song is a medium that allows them to express their true feelings in a natural and easy way with less potential for conflict. She explained this by referring to a Japanese office worker, who cannot say what he thinks directly to his boss. So instead he often drops into a Karaoke bar on the way home from work to soothe his soul by singing the song of a heart-broken woman (p. 9-10). It is interesting to note that even in his private time that the office worker who Koijma has us imagine does not sing a song directly critical of his boss, much less of the nature of work in that society. Instead he channels his negative feelings and frustrations via the strong emotions of a sad love song. 


\section{Internal Relationships}

This issue can be seen in the results of the fifth and the sixth queries. The fifth query, "My co-singers in the choir are...", addresses the internal relationship among participants and the sixth query, "The conductor of the choir is...", addresses the relationship between the conductor and the participants. Both the Norwegian and the Japanese participants seemed to maintain good relationships and have nice feelings towards each other, and we can suggest they probably have a pleasant time during choir activities. It may be more important for older adults than for people in other generations to have times that they feel comfortable and their identities assured, as opportunities for such situations decreases with age. At the same time it is still interesting that there seemed to exist subtle cultural differences between two countries concerning how they perceive their selves and how they express it.

\section{The internal relationship among participants}

The relationship among the participants may be one of the key points in choir activity. Both choirs, Norwegian and Japanese, seemed to have a good feeling of friendship. Concerning the Norwegian group, mutual care with respect for the individual seems to be the core spirit of the group. Stige (2010) noted that the participants supported each other flexibly and with humor, in subtle ways that ensure the dignity of the person needing help is not threatened (p. 248). He also noted the open-minded atmosphere of the choir, mentioning a comment by one male singer who happened to drop in a rehearsal and was warmly welcomed by the choir-ladies: "I didn't know if they would ever let me go," he said with a laugh, and explained how that motivated him to come back. Another member who knew nobody in Sandane and discovered the choir through the local newspaper talked that the choir members were siblings. Many singers talk about a strong sense of community and friendship, and claim choir singing is social, but in a way which is quite different from just coming together over a cup of coffee (p. 266-67).

For the Japanese participants this fifth query might be the one that they would like to avoid if possible, because to give opinions openly about others, especially critical ones, is considered to be reserved. Their answers were mostly favorable, however, it may be closer to the truth of the situation of the group dynamic if our observations are added. Among the Japanese participants there were several in-groups, which consisted of friends or neighbors. Although the members in general were usually friendly to each other, sometimes they showed a tendency to prefer their specific in-group within the wider group. So we may be able to say that the Japanese collectivistic culture focuses on relationships within in-groups, whereas the Norwegian individualistic culture focuses on individual open relationships.

\section{Relationship between the participants and the conductor}

Concerning the relationship to the conductor, both Norwegian and Japanese conductors were highly valued by their participants. For the Norwegian members the conductor seemed to be a key person for choir activity. The members valued her contributions not only in terms of conducting but also for the support she quickly provided them with. Stige (2010) called the conductor's role and support Professional Care and noted that a high degree of mutual trust seems to be involved (p. 267). The conductor was highly respected, but at the same time their relationship seems to be equal, built on respecting each other. Stige noted that she was not just a conductor and instructor, but also a motivator, mediator, and manager (p. 248).

Conversely, in Japan, the relationship seemed to be closer to a 'teacher-pupil' type. There may be some influence of Confucianism in the Japanese participants, as seven of them answered the conductor is a "teacher" ${ }^{4}$. As the profession of the Japanese conductor is indeed a university teacher, it may be natural for the participants to think of her as such. But inspite of her efforts of reducing the teacherness from her image, 
their conception of her as a teacher continued. It may indicate that they needed and wanted a 'teacher' figure. It may involve a certain transference type process from their ideal image of a teacher in childhood upon the conductor, and involve feeling nostalgic about this early memory of teachers who were worth respect and displayed some virtue and integrity. Confucianism teaches that high learning is worthy and so students should respect teachers. Nowadays such ideas have declined, and so the older adult participants may have missed the older 'remote' respected teacher image or regretted its decline and enjoyed a brief revival of it in our sessions.

\section{Sense of Community}

Although the concept 'Sense of community' is a specific term used in Community Psychology, we use this in a more general way here to mean the way participants think about their community, in this case specifically the choir. The result of the second query, "For me singing in a Choir is...", brought out an interesting aspect of culture. We assumed that a sense of community would be stronger in the Japanese group, as collectivistic cultures value group conformity. But the answers seemed to show the opposite: there were twice as many Norwegian statements on community as there were Japanese ones. Stige (2010) mentioned that for most of the singers in the Norwegian group their positive personal experiences and benefits in relation to areas such as memory, physical functions, and emotions were linked to the experience of the choir as community (p. 264).

For people from an individualistic society, it may be taken for granted that an individual has their own Self, which is clearly separated from others. The individual is seen as the minimum unit within a community. The size of community varies, from micro to macro, but the relationship between individual and community is constant despite that. That is to say, an individual is at the center of a group of concentrically arranged circles and is influenced by the environment of each, but basically has a large degree of autonomy within each sphere, as Urie Bronfenbrenner's (1979) model of ecological systems theory indicates.

Whereas for Japanese, Self may not so clearly mean the segregated individual as this concept is more integrated with the group. The border between Self and In-group (family, friends, or people we are very close to) is more obscure, and $I$ is often more like We. An In-group should not be divided but be uniform, which forces the constituent parts to act similarly. A wider community consists of these In-groups and although there is a clear border between different in-groups, conflicts between them are rarely seen openly. This appears to be because in Japan such conflicts are seen as threatening the wider group cohesion. Conformity may be respected in both countries, but in Norway it is perhaps attained through respecting others as individuals and through a process of individuals discussing and working through problems, whereas in Japan it is attained through following others with far less open discussion involved.

A sense of community is normally nurtured under complex conditions, so the differences as to the duration time of session, age, and geographical distance of participants might affect the results of the second query. Apart from this, it seems to us that for the Norwegian people, the bond between people in a community is considered to be something to consciously 'create'. Whereas, for the Japanese, community is something 'given', in which they manage to live somehow. Choir activity is beneficial for both people, for the Norwegians in creating community, and for the Japanese in releasing stress, although of course songs also contribute to strengthen bonds amongst Japanese people.

\section{Role of Music}

As to this issue the results of the fourth query, "Without music...", are related. The results showed the importance of music for the participants of both countries: for them a world without music is dark and hopeless, in which they would lose a reason of living. This is perhaps something that affects every generation. Recently several studies 
in anthropology and cognitive science consider how songs functioned as a type of communicative skill in the first stages of humankind (Benzon, 2001; Levitin, 2008; Mithen, 2005; Wallin, Bjørn \& Brown, 2000). Based on the new evolution theory and developed in collaboration with neuroscience and archaeology, these studies indicate how song is essential to humans. It appears that music effects all generations.

However, for older adults, especially in modern society, musical activities seem to have a more important role than for the young. For them music can be even more vital in terms of the role it plays in their quality of life. For example, helping to improve their physical condition, forming bonds with other people, regaining self-esteem, participating in society, and so on. Bunt and Stige (2014) noted that older people use music both in spite of and because of various health issues. By in spite of they mean strong interests in music despite troublesome issues they may have and because of indicates a conscious use of music as a tool for maintaining health (p. 151).

In a review of research concerned with the potential for music to contribute to the well-being of older people, Creech et al. (2013) suggested that active participation in a range of musical activities may contribute to enhanced cognitive, social, and emotional well-being (p. 93). They reported that active group music-making within community contexts may be particularly powerful for enhancing the health and well-being of older adults as they move through the Third and Fourth Ages, and active engagement with music within social settings has great potential to contribute to the fulfillment of basic psychological needs (p. 90 \& p. 98).

\section{Conclusion}

In the course of analyzing the results, it became clear that choir activity is very meaningful for the older adults of both countries. Of course there are several cultural differences, but certain similarities can be seen in aspects such as the merits of self-presentation, connecting people, and relieving stress. We may be able to suggest that music, especially conducted within a social context, plays an important role for older people beyond culture. Although the cultural differences between Norway and Japan cannot be explained by a simple dichotomy of individualism and collectivism, considering the results and also the process of answering the questions in the music completion tasks, we may be able to tentatively say that Norwegians are more independent, having a more clear sense of identity, and are more open and honest at presenting themselves than Japanese people, which gives the Norwegians an individualistic character, broadly speaking. Whereas Japanese seemed to have a less clear image of self, but had a clearer one of the group they are involved in, which led them to behave according to the situation of that group. In as much as the group overshadows the individual Japanese can be said to be collectivistic.

Culture has two phases: a positive phase that nurtures and protects your identity, and a negative one that restricts you or ties you down. As one gets old, one becomes more easily affected by one's environmental conditions, both physically and mentally, partly because of decline of health and decrease in opportunities for social participation. In both countries choir activity seemed to reduce some of the negative cultural aspects. For individualistic cultures it may provide an opportunity to help people overcome alienation, and for collectivistic cultures it releases people from cultural restraints. From a therapeutic point of view the negative aspects of culture that may cast a dark shadow on older adults can hopefully be reduced. By recognizing cultural characteristics, CoMT can be of more help to them.

\section{Acknowledgement}

The authors would like to express their appreciation to Dr. Brynjulf Stige for his advice and suggestions for this paper. We are also very grateful to Mr. Sean Michael Wilson, a well-known Scottish comic book writer and teacher of sociology and psychology, for checking the English and giving us useful advice. Our special thanks go to the participants of the both countries, Norway and Japan, who deeply inspired us. 


\section{Notes}

1. The World Population Prospect 2015 Revision report noted that globally, the number of persons aged 60 and above is expected to more than double by 2050 and more than triple by 2100 , increasing from 901 million in 2015 to 2.1 billion in 2050 and 3.2 billion in 2100. Sixty-six per cent of the increase between 2015 and 2050 will occur in Asia, $13 \%$ in Africa, $11 \%$ per cent in Latin America and the Caribbean, and the remaining 10\% in other areas (World Population Prospects The 2015 Revision-Key Findings and Advance Tables. United Nations New York, 2015, p.9). Retrieved from https://esa.un.org/unpd/wpp/Publications/Files/Key_Findings_WPP_2015.pdf on September 17, 2016

2. We may also consider that the dichotomy of individualism and collectivism is also premised upon the modern western dichotomy of an individual and the society that surrounds them. Kitayama explained that the 'interdependent Self' is based on a more monistic relationship in which people find the meaning of their existence by embedding themselves subjectively in social relationships (Kitayama, 1994, p. 154, footnote).

3. These two aspects of Japanese culture have been pointed out by many scholars and thought of as specific characteristic of this country (for example, Barnlund, 1975; Benedict, 1946; Watsuji, 1988/1961).

4. Confucianism, the origin of which goes back to ancient China, has been widely influential in Japan since the 6th century, and its idea concerning virtue and ritual influenced Japanese morality for a long time. The main aspects of Confucianism - such as filial piety, loyalty (to the ruler), humaneness, righteousness, integrity, etc. — are embedded in the Japanese mind and sometimes appear in other ways and situations.

\section{References}

Ansdell, G. (2014). How music helps in music therapy and everyday life. Farnahm: Ashgate.

Balsnes, A. H. (2012). Choral singing, health and quality of life: The story of Diana. Arts \& Health, 4(3), 249-261, http://dx.doi.org/10.1080/17533015.2012.656202.

Barnlund, D. C. (1975). Public and private self in Japan and the United States. Tokyo: The Simul Press.

Benedict, R. (1946). The chrysanthemum and the Sword: Patterns of Japanese culture. Boston: Houghton Mifflin Harcourt.

Benzon, W. L. (2001). Beethoven's anvil: Music in mind and culture. Oxford: Oxford University Press.

Bronfenbrenner, U. (1979). The ecology of human development: Experiments by nature and design. Cambridge: Harvard University Press.

Bunt, L., \& Stige, B. (2014). Music therapy: An art beyond words (2nd ed.). Hove: Routledge.

Bygren, L. O., Konlaan, B. B., \& Johansson, S. E. (1996). Attendance at cultural events, reading books or periodicals, and making music or singing in a choir as determinants for survival: Swedish interview survey of living conditions. British Medical Journal, 313(7072), 1577-1580, http://dx.doi.org/10.1136/bmj.313.7072.1577.

Clift, S., \& Hancox, G. (2010). The Significance of choral singing for sustaining psychological wellbeing: Findings from a survey of choristers in England, Australia and Germany. Music Performance Research, 3(1), 79-96.

Clift, S., \& Morrison, I. (2011). Group singing fosters mental health and wellbeing: Findings from the East Kent "Singing for Health" network project. Mental Health and Social Inclusion, 15(2), 88-97, http://dx.doi.org/10.1108/20428301111140930.

Cohen, G. D., Perlstein, S., Chapline, J., Kelly, J., Firth, K. M., \& Simmens, S. (2006). The impact of professionally conducted cultural programs on the physical health, mental health, and social functioning of older adults. The Gerontologist, 46(6), 726-734, http://dx.doi.org/ 10.1093/geront/46.6.726. 
Creech, A., Hallam, S., McQueen, H., \& Varvarigou, M. (2013). The power of music in the lives of older adults. Research studies in music education, 35(1), 87-102, http://dx.doi.org/ $10.1177 / 1321103 X 13478862$.

Elefant, C. (2010). Whose voice is heard? Performances and voices of the Renanim choir in Israel. / Giving voice: Participatory action research with a marginalized group. In B. Stige, G. Ansdell, C. Elefant, \& M. Pavlicevic (Eds.), Where music helps (pp. 189-215). Farnham: Ashgate.

Grape, R. N., Theörell, T., Wikström, B. M., \& Ekman, R. (2009). Choir singing and Fibrinogen. VEGF, Cholecystokinin and Motilin in IBS patients. Medical Hypotheses, 72, 223-225, http://dx.doi.org/10.1016/j.mehy.2008.09.019.

Hall, E. T. (1976). Beyond culture. New York: Anchor Books.

Hara, M. (2011). Expanding a care network for people with dementia and their carers through musicking: Participant observation with "Singing for the Brain". Voices: A World Forum for Music Therapy, 11(2), http://dx.doi.org/10.15845/voices.v11i2.570.

Hays, T., \& Minichiello, V. (2005). The contribution of music to quality of life in older people: An Australian qualitative study. Ageing \& Society, 25, 261-278.

Hofstede, G., Hofstede, G. J., \& Minkov, M. (2010). Cultures and organizations: Software of the mind (3rd ed.). New York: McGraw-Hill Companies.

Inoue, S. (2007). A study of Japanese concepts of community. Voices: A World Forum for Music Therapy, 7(2), http://dx.doi.org/10.15845/voices.v7i2.491.

Johnson, J. K., Louhivuori, J., Stewart, A. L., Tolvanen, A., Ross, L., \& Era, P. (2013). Quality of life (QOL) of older adult community choral singers in Finland. International Psychogeriatrics, 25(7), 1055-1064, http://dx.doi.org/10.1017/S1041610213000422.

Kimura, H. (2014). Ongakuryoho no Kanousei: Nihonjin ni totteno kea tositeno Uta. [The possibility of music therapy: Song as care for Japanese people]. Sentan RinriKenkyu, [Studies of Advanced Ethics], 8, 197-208.

Kitayama, S. (1994). Bunkateki Jikokan to Shinriteki Purosesu. [Cultural views of self and psychological process]. Shakaisinrigaku Kenkyu, [Japanese Journal of Social Psychology], 10(3), 153-167.

Kitayama, S., \& Cohen, D. (Eds.). (2007). Handbook of cultural psychology. New York: The Guilford Press.

Kojima, T. (1994). Ongaku kara mita Nihonjin [The Japanese seen through their music]. Tokyo: Nihon Housou Shuppan kyoukai.

Kuga, H. (2005). Nihon no Social work ni okeru bunkatekikiban: 'Seken' ni ikiru nihon no 'Kojin' eno Shiten. [The study of cultural base of social work in Japan: The viewpoint to 'individual' in Japan living in 'Seken']. Hyoron Shakaigaku, [Social Science Review], 77, 43-63.

Lehtonen, K. (2002). Some ideas about music therapy for elderly. Voices: A World Forum for Music Therapy, 2(1), http://dx.doi.org/10.15845/voices.v2i1.71.

Levitin, D. J. (2008). The world in six songs: How the musical brain created human nature. Dutton: Penguin.

Livesey, L., Morrison, I., Clift, S., \& Camic, P. (2012). Benefits of choral singing for social and mental wellbeing: Qualitative findings from a cross-national survey of choir members. Journal of Public Mental Health, 11, 10-26, http://dx.doi.org/10.1108/ 17465721211207275.

MacDonald, R., Kreutz, G., \& Mitchell, L. (Eds.). (2012). Music, health, and wellbeing. New York: Oxford University Press. http://dx.doi.org/10.1093/acprof:oso/ 9780199586974.001.0001.

Markus, H. R., \& Kitayama, S. (1991). Culture and the self: Implications for cognition, emotion, and motivation. Psychological Review, 98(2), 224-253, https://doi.org/10.1037/ 0033-295X.98.2.224. 
Matsui, T. (2010). Shudan Kasho Ryoho wo Kangaeru: Rekishiteki Shiten kara. [Considering Group singing from a historical point of view]. Nihon Ongaku Ryoho Gakkaishi, [Japanese Journal of Music Therapy], 10(1), 61-69.

McCullough, E. C. (1981). An assessment of the musical needs and preferences of individuals 65 over. Tuscon: University of Arizona.

Mithen, S. (2005). The singing Neanderthals: The origins of music, language, mind and body. London: Weidenfeld \& Nicolson Ltd.

Nisbett, R. E. (2003). The geography of thought: How Asians and Westerners think differently... and why. New York: Free Press.

Numata, R. (2010). Komyunithi Ongakuryoho ni okeru Ongaku no Geijututeki kachi to Shakaiteki igi: Autosaidaa-Aato ni kansuru Giron wo tegakari ni. [Artistic value and social meaning of music in community music therapy: A discussion referring to the discourses on outsider art]. Nihon Ongaku Ryoho Gakkaishi, [Japanese Journal of Music Therapy], 10(1), 95-109.

Oyserman, D., Coon, H. M., \& Kemmelmeier, M. (2002). Rethinking individualism and collectivism: Evaluation of theoretical assumptions and meta-analyses. Psychological Bulletin, 128(1), 3-72, https://doi.org/10.1037/0033-2909.128.1.3.

Pavlicevic, M. (2004). Learning from Thembalethu: towards responsive and responsible practice in community music therapy. In M. Pavlicevic \& G. Ansdell (Eds.), Thembalethu (pp. 35-47). London: Jessica Kingsley Publishers.

Pavlicevic, M., \& Ansdell, G. (Eds.). (2004). Community music therapy. London: Jessica Kingsley Publishers.

Ruokonen, I., \& Ruismäki, H. (2011). Lifelong learning and musical interaction -Integrated musical activity increases the well-being of older people. Procedia-Social and Behavioral Sciences, 12, 340-345, http://dx.doi.org/10.1016/j.sbspro.2011.02.043.

Ruud, E. (2010). Music therapy: A perspective from the humanitie. Gilsum: Barcelona Publishers.

Ruud, E. (2012). The new health musicians. In R. MacDonald, G. Kreutz, \& L. Mitchell (Eds.), Music, Health, \& Wellbeing (pp. 87-96). New York: Oxford University Press. https://doi.org/ 10.1093/acprof:oso/9780199586974.003.0007.

Samovar, L. A., \& Porter, R. . E. (2004). Communication between cultures (5th ed.). Wadsworth: Thomson Learning.

Shiota, S., \& Ueda, T. (2011). Nihonjin no Bunkateki Tokusei kara miru Peer Group Supervision ni tsuite no Kenkyu. [A study on peer group supervision in Japanese cultural contexts]. Hanazono Daigaku Shakaihukushi Gakubu Kenkyu Kiyou, [Bulletin of Faculty of Social Welfare, Hanazono University], 19, 127-140.

Stige, B. (2002). Culture-centered music therapy. Gilsum: Barcelona Publishers.

Stige, B. (2010). Caring for music: The senior choir in Sandane, Norway. Practicing music as mutual care. In B. Stige, G. Ansdell, C. Elefant, \& M. Pavlicevic (Eds.), Where music helps (pp. 245-274). Farnham: Ashgate.

Stige, B. (2012). Health musicking: A perspective on music and health as action and performance. In R. MacDonald, G. Kreutz, \& L. Mitchell (Eds.), Music, Health, \& Wellbeing (pp. 183-195). New York: Oxford University Press. https://doi.org/10.1093/acprof:oso/ 9780199586974.003.0014.

Stige, B., Ansdell, G., Elefant, C., \& Pavlicevic, M. (2010). Where Music Helps. Farnham: Ashgate.

Takano, Y. (2008). 'Shudanshgugi' toiu Sakkaku; Nihonjinron no omoichigai to sono Yurai [The illusion of collectivism: Misconception and its root in theories of Japanese cultural uniqueness]. Tokyo: Shinyosha.

Triandis, H. C. (1995). Individualism and collectivism. Boulder: Westview Press.

United Nation (2015) World Population Prospects The 2015 Revision-Key Findings and Advance Tables. United Nations New York. Retrieved from https://esa.un.org/unpd/wpp/

Publications/Files/Key_Findings_WPP_2015.pdf 
Wallin, N. L., Björn, M., \& Brown, S. (Eds.). (2000). The origins of music. Cambridge: MIT press.

Watsuji, T. (1988/1961). Hudo; Ningengakuteki Kousatsu [Culture: A philosophical study]. Tokyo: Iwanami Shoten.(G. Bownas, Trans.). New York: Greenwood Press.

Wise, G. W., Hartmann, D. J., \& Fisher, B. J. (1992). Exploration of the relationship between choral singing and successful Aging. Psychological Reports, 70, 1175-1183, https://doi.org/ 10.2466/pr0.1992.70.3c.1175.

Yamagishi, T. (2002). Kokoro Dekkachi na Nihonjin: Shudanshugi to iu Gensou [Spirit-heavy Japanese: the Illusion of Collectivism]. Tokyo: Nihon Keizai Shinbunsha.

Zanini, C., \& Leao, E. (2006). Therapeutic choir: A music therapist looks at the new millennium eldery. Voices: A World Forum for Music Therapy, 6(2), http://dx.doi.org/ 10.15845/voices.v6i2.249. 